\title{
Synthesis of all-cis-1,2,4-cyclohexanetriol
}

\author{
Maria Teresa Rocchetti ${ }^{\mathrm{a}}$, Gaston Diels ${ }^{\mathrm{b}}$ and Norbert De Kimpe ${ }^{\mathrm{a} *}$ \\ ${ }^{a}$ Department of Organic Chemistry, Faculty of Agricultural and Applied Biological Sciences, \\ University of Ghent, Coupure Links 653, B-9000 Ghent, Belgium. \\ ${ }^{b}$ Synthesis Enabling Technologies, Johnson \& Johnson Pharmaceutical Research \& \\ Development, Turnhoutseweg 30, B-2340 Beerse, Belgium. \\ E-mail : norbert.dekimpe@rug.ac.be
}

\section{Dedicated to Professor Georges Hoornaert on the occasion of his $65^{\text {th }}$ birthday}

(received 15 Nov 02; accepted 20 Dec 03; published on the web 04 Feb 03)

\begin{abstract}
A one step synthesis of ( \pm )-all-cis-1,2,4-cyclohexanetriol 1 by high pressure hydrogenation of the corresponding 1,2,4-benzenetriol in the presence of Raney-nickel or a catalytic amount of rhodium on aluminium oxide is disclosed.
\end{abstract}

Keywords: Cyclohexane-1,2,4-triol, high pressure hydrogenation, Raney-nickel, rhodium on aluminium oxide

\section{Introduction}

Polyhydroxycyclohexanes are of great interest as model compounds for studies in carbohydrate chemistry and stereochemistry, and are of importance because of their relationship to the biologically important cyclitol and myo-inositol. ${ }^{1}$

In the literature, ${ }^{2}$ an extensive study on the synthesis and conformational NMR-analysis of the series of nine isomeric cyclohexanetriols (there are 14 cyclohexanetriol isomers if the two enantiomers of each racemic pair are separately counted) was performed. For cyclohexanetriol, three structures are possible: cyclohexane-1,2,3-triol (vicinal); cyclohexane-1,3,5-triol (symmetric), and cyclohexane-1,2,4-triol (asymmetric). cis-1,2,4-Cyclohexanetriol $\mathbf{1}$ is a target molecule for the synthesis of the corresponding orthoester derivatives, which are the "core" of resiniferatoxin 2 (Figure 1), isolated from Euphorbia resinifera. ${ }^{3}$ Resiniferatoxin acts as an ultrapotent analogue of capsaicin, the pungent constituent of hot peppers. ${ }^{4}$ Both of the latter substances possess the ability to excite and subsequently desensitize sensory nociceptor neurons, leading to analgesia. ${ }^{5}$ 
<smiles>O[C@H]1CC[C@@H](O)C[C@H]1O</smiles>

1

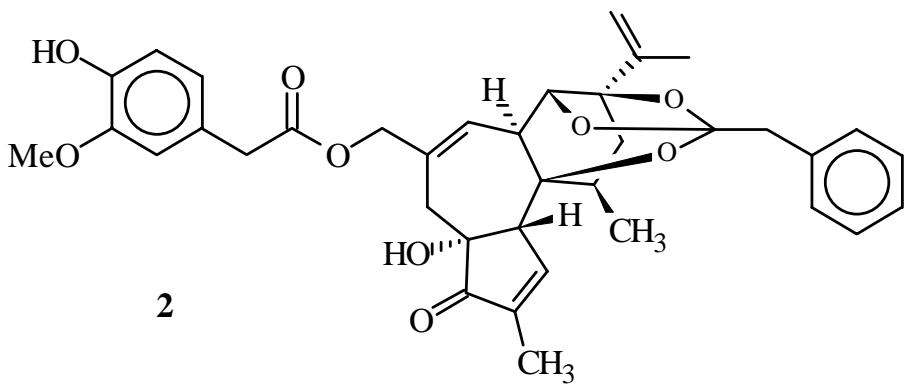

\section{Figure 1}

The asymmetric synthesis of (+)-all-cis-1,2,4-cyclohexanetriol was pointed out in the literature in the synthesis of aminocyclitols starting from (-)-quinic acid. ${ }^{6}$ The reaction sequence involved seven steps affording the optically active (+)-all-cis-1,2,4-cyclohexanetriol in reasonable yield (40\%). Apparently, the preparation of the racemic all-cis-1,2,4-cyclohexanetriol $\mathbf{1}$ by hydrogenation or reduction of 1,2,4-trihydroxybenzene 3 has never been reported. On the other hand, the high pressure hydrogenation of the symmetric 1,3,5-trihydroxybenzene (pyrogallol) to all-cis-cyclohexane-1,3,5-triol was readily performed using Raney-nickel as catalyst (about $40 \%$ yield). ${ }^{7}$ The only method reported in the literature for the synthesis of $( \pm$ )all-cis-1,2,4-cyclohexanetriol 1 used a cis dihydroxylation of 3-cyclohexen-1-ol ${ }^{2}$ or its benzoate ester or benzyl ether. The two diastereomers with 1,2-cis configuration were separated by fractional crystallization affording the racemic mixture of ( \pm )-all-cis-cyclohexane-1,2,4-triol 1 in very low yield ( $8 \%$ ).

Because of the potential importance of a readily available source of racemic all-ciscyclohexane-1,2,4-triol $\mathbf{1}$ as basic core of the daphnane diterpenes family, potent tumor promoters, ${ }^{8}$ and cage orthoesters, as present in resiniferatoxin (RTX) and various other esters of resiniferonol, ${ }^{9}$ a short synthesis of triol 1 was developed.

\section{Results and Discussion}

In the present communication a one step synthesis of $( \pm$ )-all-cis-1,2,4-cyclohexanetriol $\mathbf{1}$, based on the high pressure hydrogenation of 1,2,4-trihydroxybenzene 3 is described.

High pressure hydrogenation of 1,2,4-trihydroxybenzene 3 at 100 atmospheres was performed with Raney-nickel in ethanol at $100^{\circ} \mathrm{C}$ (Scheme 1). The workup of the reaction mixture obtained was not easy because of the high viscosity and the water solubility of the reaction products. After filtration, the viscous reaction mixture was preferably quickly distilled under high vacuum and, successively, the complex reaction mixture was separated by flash chromatography on silica gel affording the pure $( \pm$ )-all-cis-cyclohexane-1,2,4-triol 1 in $31 \%$ yield. 


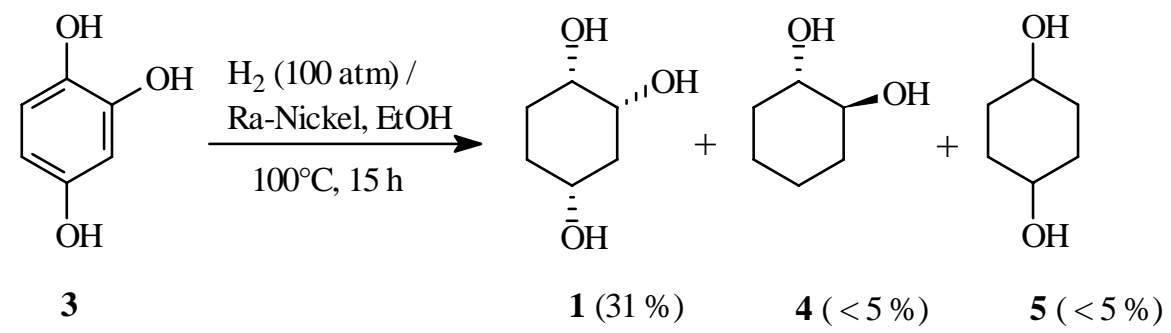

\section{Scheme 1}

The other compounds isolated by flash chromatography were trans-cyclohexane-1,2-diol 4, and cyclohexane-1,4-diol 5, both in a minor yield of $5 \%$ (Scheme 1).

To avoid substantial loss of the triol $\mathbf{1}$ during the silica gel chromatography, the separation of the reaction mixture was performed also by centrifugal counter current chromatography (Centrifugal CCC). The yield of the triol 1 could not be improved higher than $30 \%$. This represents an alternative way for the isolation of the ( \pm )-all-cis-cyclohexane-1,2,4-triol $\mathbf{1}$.

$( \pm)$-cis-Cyclohexane-1,2,4-triol $\mathbf{1}$ is a white solid, readily soluble in water, in polar solvents such as methanol, dimethylsulfoxide and dimethylformamide. It also shows a moderate solubility in tetrahydrofuran. The melting point, and $60 \mathrm{MHz}{ }^{1} \mathrm{H}$ NMR spectral data obtained for ( \pm )-all-ciscyclohexane-1,2,4-triol 1 were identical with those reported in the literature. ${ }^{2}$ Further spectrometric data (270 MHz ${ }^{1} \mathrm{H}$ NMR, $68 \mathrm{MHz}{ }^{13} \mathrm{C}$ NMR, MS) of ( \pm )-all-cis-1,2,4cyclohexanetriol $\mathbf{1}$ are described in the experimental part.

To improve the results of the catalytic hydrogenation, other metals were used for this high pressure reaction. The hydrogenation reaction of trihydroxy-1,2,4-benzene 3 was performed with rhodium on aluminium oxide (5\%) as catalyst in tetrahydrofuran at 100 atmospheres of pressure (Scheme 2). The same complex mixture of isomers was obtained, but with the ( \pm )-all-cis-1,2,4cyclohexanetriol $\mathbf{1}$ as predominant compound. The high pressure was necessary for the completion of the reaction. In fact, the same reaction with $\mathrm{Rh} / \mathrm{Al}_{2} \mathrm{O}_{3}$ performed at one atmosphere of pressure gave, after one week at $50^{\circ} \mathrm{C}$, a reaction mixture in which the main compound was still the 1,2,4-trihydroxybenzene 3 .<smiles>Oc1ccc(O)c(O)c1</smiles>

3

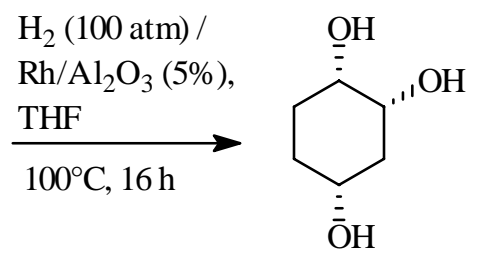

1 (50\%) 


\section{Scheme 2}

Using $\mathrm{Rh} / \mathrm{Al}_{2} \mathrm{O}_{3}$ as catalyst, the high vacuum distillation of the reaction mixture was not necessary, and the mixture of reaction products was immediately separated by flash chromatography on silica gel, affording the desired all-cis-triol 1 in an improved yield of $50 \%$.

In conclusion, a convenient one step synthesis of $( \pm$ )-all-cis-cyclohexane-1,2,4-triol 1, a useful scaffold for natural products synthesis, is reported.

\section{Experimental Section}

General Procedures. NMR spectra were run on a JEOL JNM EX 270 spectrometer, using $\mathrm{CD}_{3} \mathrm{OD}$ as the solvent. TLC was performed on $\mathrm{Si}$ gel plates Kieselgel $60 \mathrm{~F}_{254}$. Flash chromatography was carried out on Si gel (Merck; particle size 40-63 $\mu \mathrm{m}$ ). Raney-nickel, $\mathrm{Rh} / \mathrm{Al}_{2} \mathrm{O}_{3}$, and 1,2,4-trihydroxybenzene were of commercial grade (Aldrich or Acros) and used without further purification.

( \pm )-All-cis-cyclohexane-1,2,4-triol (1). The hydrogenation of trihydroxy-1,2,4-benzene 3 was performed in a Parr apparatus. To a solution of 1,2,4-trihydroxybenzene (10 g, $76 \mathrm{mmol})$ in 50 $\mathrm{ml}$ of absolute ethanol, $15 \mathrm{~g}$ of Raney-nickel (type $\mathrm{W}_{4}$ ) was added, and the mixture was stirred for 15 hours at 100 atmospheres of pressure at $100^{\circ} \mathrm{C}$. The cooled reaction mixture was filtered on celite and the solvent was evaporated in vacuo. The dark viscous reaction mixture was distilled at high vacuum to afford the crude triol 1, b.p. $130^{\circ} \mathrm{C}$ at $0.01 \mathrm{mmHg}$, contaminated by other reaction products (NMR).

This mixture was further separated by flash chromatography. A mixture of $\mathrm{CH}_{2} \mathrm{Cl}_{2} / \mathrm{MeOH}$ (95:5) was used to eluate the first two compounds [compound $4\left(\mathrm{R}_{\mathrm{f}}=0.44\right.$, in $\mathrm{CH}_{2} \mathrm{Cl}_{2} / \mathrm{MeOH}$ 9:1) and $5\left(\mathrm{R}_{\mathrm{f}}=0.29\right.$, in $\mathrm{CH}_{2} \mathrm{Cl}_{2} / \mathrm{MeOH}$ 9:1), Scheme 1], then $\mathrm{CH}_{2} \mathrm{Cl}_{2} / \mathrm{MeOH}$ (9:1) was necessary to eluate the desired triol $1\left(\mathrm{R}_{\mathrm{f}}=0.16\right)$ in $31 \%$ yield. Anal. Calcd. for $\mathrm{C}_{6} \mathrm{H}_{12} \mathrm{O}_{3}(132)$ : C, 54.53; H, 9.15. Found: C, 54.65; H, 9.54. ${ }^{1} \mathrm{H}$ NMR (270 MHz, $\left.\mathrm{CD}_{3} \mathrm{OD}\right) \delta 1.30-1.95$ (6 H, m, 3 $\left.\times \mathrm{CH}_{2}\right), 3.59(2 \mathrm{H}, \mathrm{m}, 2 \times \mathrm{CHOH}), 3.77(1 \mathrm{H}, \mathrm{m}, \mathrm{CHOH}),{ }^{13} \mathrm{C} \mathrm{NMR}\left(68 \mathrm{MHz}, \mathrm{CD}_{3} \mathrm{OD}\right) \delta 27.9$ $\left(\mathrm{CH}_{2}\right), 29.5\left(\mathrm{CH}_{2}\right), 38.1\left(\mathrm{CH}_{2}\right), 69.1(\mathrm{CHOH}), 69.6(\mathrm{CHOH}), 71.5(\mathrm{CHOH})$. Mass spectrum $\mathrm{m} / \mathrm{z}$, 70 eV (\%): 132 (M+, 2), 114 (37), 96 (7), 88 (14), 86 (14), 83 (9), 75 (33), 74 (10), 73 (39), 71 (47), 70 (100), 69 (12), 68 (17), 67 (12), 60 (10), 58 (60), 57 (60), 55 (21), 45 (52), 44 (96), 43 (56), 42 (19), 41 (32), 39 (15).

The separation of the reaction products $\mathbf{1}, \mathbf{4}$, and $\mathbf{5}$, obtained from the hydrogenation reaction, by centrifugal counter current chromatography was performed as follows. An amount of $100 \mathrm{mg}$ of the reaction mixture was separated using the following solvent system: $\mathrm{CHCl}_{3} / \mathrm{MeOH} / \mathrm{i}$ $\mathrm{PrOH} / \mathrm{H}_{2} \mathrm{O}$ (5 : $\left.6: 1: 4\right)$ affording $30 \mathrm{mg}$ of ( \pm )-all-cis-cyclohexane-1,2,4-triol 1.

The high pressure hydrogenation reaction with $\mathrm{Rh} / \mathrm{Al}_{2} \mathrm{O}_{3}$ was performed in an analogous way as the procedure described with Raney-nickel. The only difference was the amount of rhodium 
on aluminium oxide used in a catalytic amount $\left(0.5 \mathrm{~g}\right.$ of $\mathrm{Rh} / \mathrm{Al}_{2} \mathrm{O}_{3}$ for $10 \mathrm{~g}$ of $1,2,4-$ trihydroxybenzene). After filtration and evaporation of the solvent, the mixture of reaction products obtained was separated by flash chromatography on silica gel using a mixture of $\mathrm{CH}_{2} \mathrm{Cl}_{2} / \mathrm{MeOH}$ (4:1) to give compound 1 in $50 \%$ yield.

\section{References}

1. Harvey, B. H.; Brink, C. B.; Seedat, S.; Stein, D.J. Progress in Neuro-Psychopharmacology \& Biological Psychiatry 2002, 26, 21.

2. McCasland, G.E.; Naumann, M.O.; Durham, L.J. J. Org. Chem. 1966, 31, 3079.

3. Victory, S.F.; Appendino, G.; Vander Velde, D.G. Bioorg. Med. Chem. 1998, 6, 223.

4. Szallasi, A.; Blumberg, P. M. Neuroscience 1989, 30, 515.

5. Bloomfield, G. C.; Ritchie, T. J.; Wrigglesworth, R. J. Chem. Soc. Perkin Trans. I 1992, 1229.

6. (a) Mercier, D.; Leboul, J.; Cleophax, J.; Gero, S.D. Carbohydr. Res. 1971, 20, 299. (b) Castellanos, L.; Cleophax, J.; Colas, C.; Leboul, J.; Mercier, D.; Gero, S.D. Carbohydr. Res. 1980, 82, 283.

7. Christian, R.; Gogek, C.J.; Purves, C.B. Can. J. Chem. 1951, 29, 911. Dumortier, L.; Van der Eycken, J.; Vandewalle, M. Tetrahedron Lett. 1989, 30, 3201.

8. Wender, P. A.; Lee, H. Y.; Wilhelm, R. S.; Williams, P. D. J. Am. Chem. Soc. 1989, 111, 8954.

9. $\quad$ Adolf, W.; Sorg, B.; Hergenhahn, M.; Hecker, E. J. Nat. Prod. 1982, 45, 347. 